\title{
ANÁLISE DE BACIA APLICADA ÀS UNIDADES MESOZÓICAS DO TRIÂNGULO MINEIRO (SUDESTE DO BRASIL): UMA ESTRATÉGIA NA PROSPECÇÃO DE RECURSOS HÍDRICOS SUBTERRÂNEOS
}

\author{
Alessandro Batezelli ${ }^{1}$, Antônio Roberto Saad², Vicente José Fulfaro ${ }^{3}$, \\ Alessandra Cristina Corsi ${ }^{4}$, Paulo Milton Barbosa Landim ${ }^{3}$, e José Alexandre de Jesus Perinotto ${ }^{3}$
}

Recebido em 22/06/2004, aceito em 31/12/2004

\begin{abstract}
RESUMO Com uma área de $1.600 .000 \mathrm{Km}^{2}$ na região sudeste do Brasil, a Bacia Sedimentar do Paraná tem posição de destaque mundial com relação sua potencialidade para recursos hídricos, por abrigar estratos rochosos com características de permo-porosidade adequadas ao armazenamento de água. A partir da análise de bacia sedimentar integrada, utilizando informações de afloramentos e poços tubulares profundos, foi feita a caracterização de três sistemas de aqüíferos (Botucatu, Serra Geral e Bauru) para uma região que abrange o extremo oeste do Estado de Minas Gerais (Triângulo Mineiro), e áreas adjacentes nos estados de São Paulo, Goiás e Mato Grosso do Sul. As informações obtidas subsidiaram a confecção de mapas de distribuição de fácies reservatórios, isoespessuras, contorno estrutural e lineamentos estruturais. Dessa forma, foi possível avaliar características dos sistemas de aqüíferos, tais como, espessuras médias, cota topográfica de topo das formações, bem como suas vazões médias, apontando áreas favoráveis a execução de projetos para explotação das águas, de acordo com as necessidades de cada região.
\end{abstract}

Palavras-chaves: Análise de Bacia, Sistemas de aqüíferos, unidades mesozóicas, Triângulo Mineiro.

\begin{abstract}
Basin Analysis Applied To The Mesozoic Units Of Triângulo Mineiro (Southeast Of Brazil): A New Strategy Of Groundwater Exploration. The Paraná Basin has been occupied an important position in the world because of the groundwater potential in their geological units, distributed in area with $1.600 .000 \mathrm{Km}^{2}$ in the southeast portion of Brazil. Based on surface and sub-surface data, the basin analysis applied to the western portion of the Minas Gerais (Triângulo Mineiro area), and adjacent portions in the states of São Paulo, Mato Grosso do Sul and Goiás, has allowed to characterize the groundwater systems (Botucatu, Serra Geral and Bauru units). The information has shown as reservoirs facies, structural contorn and structural lineaments maps. Thus it was possible to define characteristic like median thick of reservoir, topographic level of the top units, median outflow, that has allowed to select the better areas to groundwater exploration projects. Because of the increase in the water's waste in the Triângulo Mineiro region, the basin analysis method applied in the Mesozoic units suggest the Botucatu groundwater system should be the mainly target of groundwater exploration projects.
\end{abstract}

Keyword: Basin Analysis, Groundwater Systems, Mesozoic units, Triângulo Mineiro area.

\section{INTRODUÇÃO}

Muito embora o Brasil seja um país privilegiado, com cerca de $53 \%$ da água doce superficial da América do Sul concentrada em seu território (HIRATA, 2002), a falta de uma política de gerenciamento de recursos hídricos adequada, aliada às extrações desmedidas dos corpos de água e contaminação dos rios por poluentes, faz com que esse bem se torne cada vez mais escasso. Dessa maneira, uma alternativa para o abastecimento dos centros urbanos tem sido a explotação de recursos hídricos subterrâneos.

Nesse sentido a Bacia Sedimentar do Paraná, abrangendo uma área de $1.600 .000 \mathrm{Km}^{2}$ na região sul da América do Sul, tem posição de destaque por abrigar estratos rochosos com características de permo-porosidade adequadas ao armazenamento de água, constituindo assim, vários sistemas de aqüíferos (Figura 1).

A partir da análise de bacia integrada, utilizando informações de superfície e subsuperfície, foi feita a caracterização de três sistemas de aqüíferos (Botucatu ou Guarani, Serra Geral e Bauru) para a região conhecida como Triângulo Mineiro no extremo oeste do Estado de Minas Gerais. Para uma melhor compreensão e detalhamento dos sistemas de aqüíferos, foram utilizados dados de áreas adjacentes no norte do Estado de São Paulo, sul de Goiás e nordeste do Mato Grosso do Sul (Figura 1).

Como principais produtos dessa pesquisa destacaram-se mapas de distribuição de fácies reservatórios, isoespessuras, contorno estrutural e

\footnotetext{
${ }^{1}$ Dpto. de Geociências - Centro de Ciências Exatas da Universidade Estadual de Londrina (alessandro.batezelli@gmail.com) ${ }^{2}$ Departamento de Geologia Aplicada - Instituto de Geociências e Ciências Exatas - UNESP / Universidade Guarulhos UnG (asaad@prof.ung.br)

${ }^{3}$ Departamento de Geologia Aplicada - Instituto de Geociências e Ciências Exatas - UNESP

(fulfaro@rc.unesp.br); (plandim@rc.unesp.br); (perinoto@rc.unesp.br)

${ }^{4}$ IPT - Instituto de Pesquisas Tecnológicas do Estado de São Paulo - DEGEO (accorsi@ipt.br)
} 
lineamentos estruturais, permitindo avaliar características dos sistemas de aqüíferos, tais como, espessuras médias, cota topográfica de topo das formações, bem como suas vazões médias
Essas informações permitiram a seleção de áreas favoráveis à execução de projetos para explotação das águas, de acordo com as necessidades de cada região.

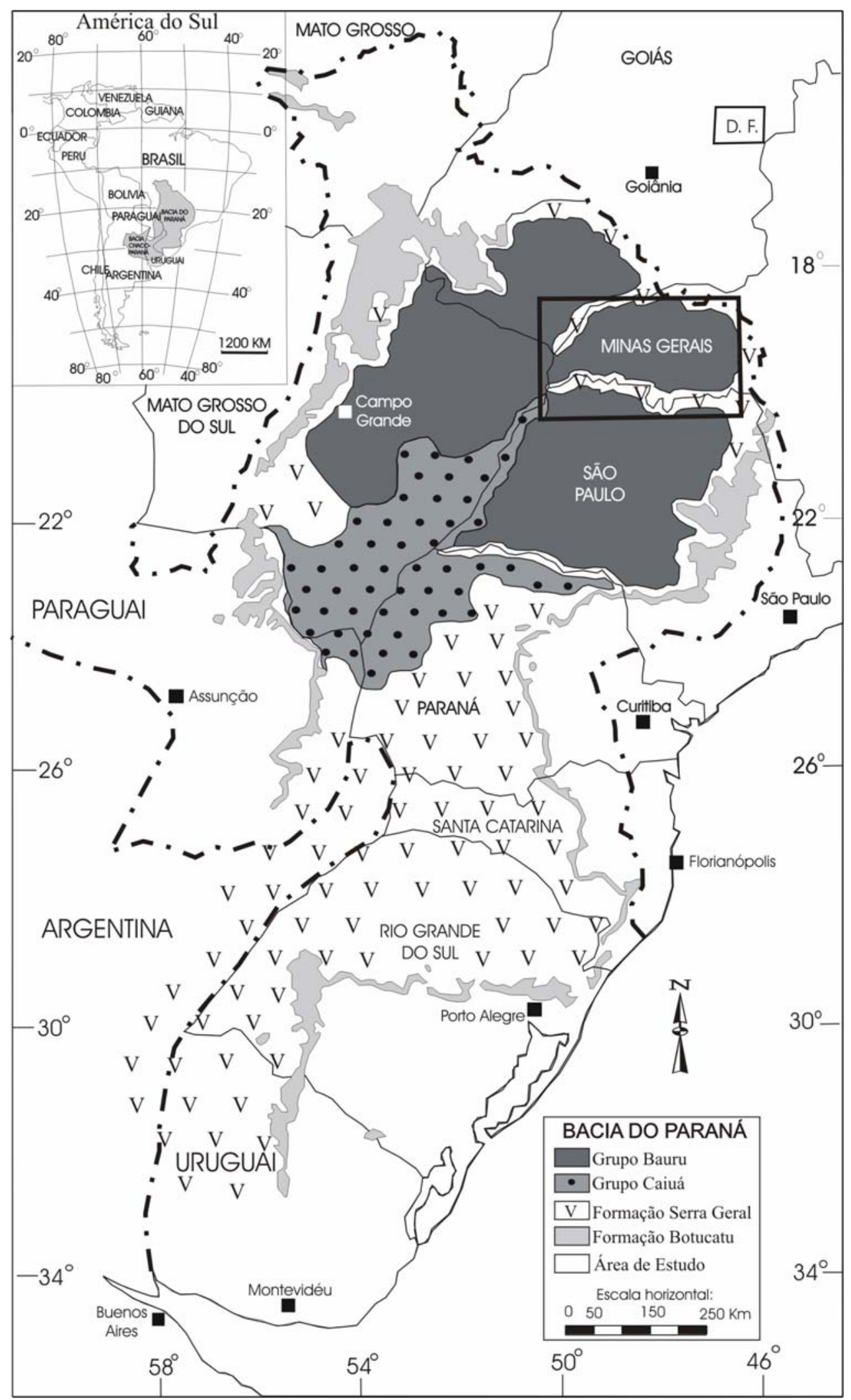

Figura 1 - Mapa de distribuição das unidades litoestratigráficas mesozóicas da Bacia do Paraná e localização da área de estudo. 


\section{CONTEXTO REGIONAL}

A área de estudo está situada na porção setentrional de uma grande bacia intracratônica, fanerozóica, conhecida como Bacia Sedimentar do Paraná, desenvolvida totalmente sobre crosta continental no sudeste da Placa Sul-Americana, abrangendo partes do território brasileiro, paraguaio, uruguaio e argentino. A porção brasileira dessa bacia representa aproximadamente $94 \%$ de toda a sua extensão e distribui-se pelos estados de Rio Grande do Sul, Santa Catarina, Paraná, São Paulo, Minas Gerais, Mato Grosso do Sul, Mato Grosso e Goiás (Figura 1). Possui uma forma alongada na direção NNE/SSW e é preenchida por rochas sedimentares e vulcânicas, cujas idades variam do Ordoviciano até o Cenozóico, com aproximadamente 5000 metros de espessura em sua porção central (ZALÁN et al., 1990).

Segundo MILANI (1997), o registro total da Bacia do Paraná inclui estratos que se distribuem do Neo-Ordoviciano (450 Ma) ao Neo-Cretáceo (65 Ma), compondo uma unidade estratigráfica de ordem I que demarca a própria entidade "Bacia do Paraná", como aquele local da superfície terrestre no qual aconteceram sucessivos episódios de subsidência no
Fanerozóico e que permitiriam a acumulação e preservação do pacote que se pode hoje nela observar.

As unidades geológicas aqui enfocadas constituem estratos depositados no intervalo de tempo compreendido entre o Jurássico e o Cretáceo Superior (Figura 2), podendo ser assim sintetizadas:

\section{FORMAÇÃO BOTUCATU}

A Formação Botucatu foi definida inicialmente como "Grês de Botucatu", originalmente descrito e relatado por CAMPOS (1889), como todos os arenitos com estratificação cruzada de grande porte que ocorrem abaixo ou interacamados aos derrames basálticos. Constituise por arenitos médios a finos de elevada esfericidade e aspecto fosco, róseos, que exibem estratificação cruzada tangencial de médio a grande porte. Junto à base, localmente ocorrem ventifactos (ALMEIDA e MELO, 1981) derivados de um persistente retrabalhamento eólico sobre depósitos fluviais subjacentes ao campo de dunas. Essa unidade juntamente com a Formação Serra Geral constituem o Grupo São Bento.

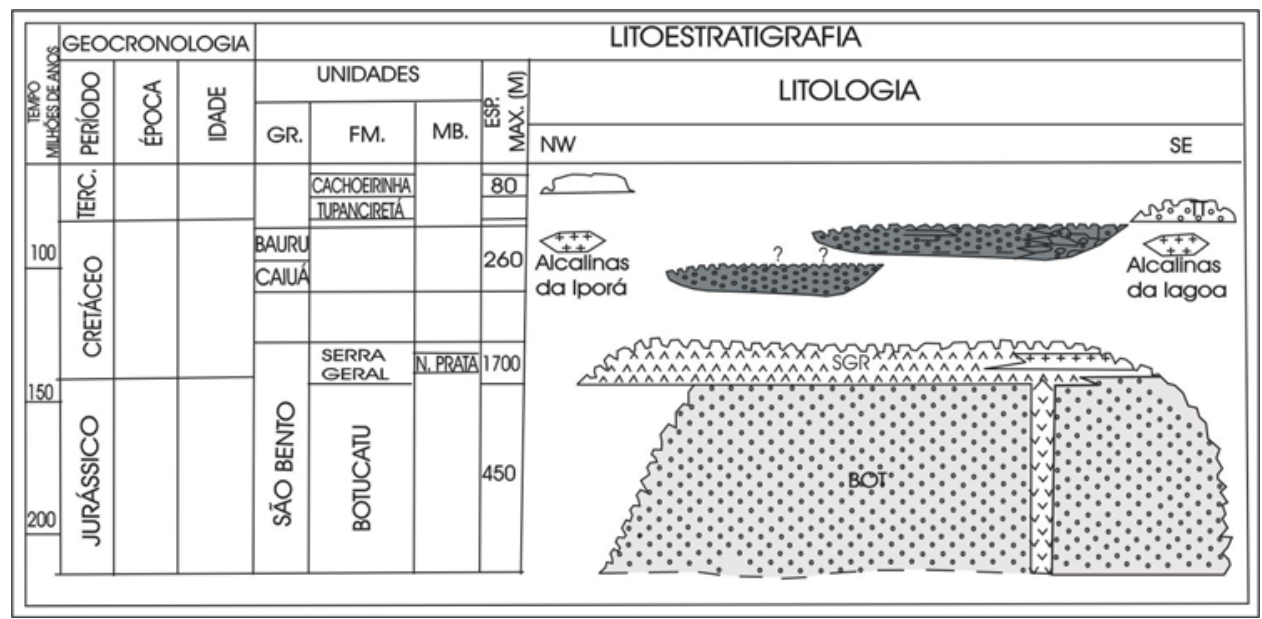

Figura 2 - Coluna Litoestratigráfica das Unidades Mesozóicas da Bacia do Paraná (MILANI, 1997 - Modificado).

Do ponto de vista hidrogeológico, a Formação Botucatu, contendo o Aqüífero Guarani, é um dos maiores reservatórios de água subterrânea do mundo, com uma extensão de $1.200 .000 \mathrm{~km}^{2}$ abrangendo partes do território brasileiro, argentino, paraguaio e uruguaio. A porção brasileira distribui-se por 8 estados: Mato Grosso do Sul (213.200 $\left.\mathrm{km}^{2}\right)$, Rio Grande do Sul (157.600 km²), São Paulo (155.800 km²), Paraná $\left(131.300 \mathrm{~km}^{2}\right)$, Goiás $\left(55.000 \mathrm{~km}^{2}\right)$, Minas Gerais $\left(51.300 \mathrm{~km}^{2}\right)$, Santa Catarina $\left(49.200 \mathrm{~km}^{2}\right)$ e
Mato Grosso $\left(26.400 \mathrm{~km}^{2}\right)$. O termo Aqüífero Guarani é uma denominação unificadora de diferentes formações geológicas cunhado pelo geólogo uruguaio Danilo Antón em homenagem a Grande Nação Guarani, que habitava essa região. Esse sistema aqüífero foi inicialmente denominado Aqüífero Gigante do Mercosul, por ocorrer nos quatro países participantes do referido acordo comercial (ARAUJO et al., 1995). 
Sua espessura varia de 50 a $800 \mathrm{~m}$, estando situadas em profundidades que podem alcançar até $1800 \mathrm{~m}$. Devido ao gradiente geotérmico, as águas desse aqüífero podem alcançar temperaturas relativamente altas, em general entre 50 e $65^{\circ} \mathrm{C}$.

As reservas permanentes de água do Aqüífero Guarani são da ordem de $45.000 \mathrm{~km}^{3}$ (45 trilhões de metros cúbicos), considerando uma espessura média do aqüífero de $250 \mathrm{~m}$ e porosidade efetiva de $15 \%$. As reservas explotáveis correspondem à recarga natural (media anual) e foram calculadas em $166 \mathrm{~km}^{3} /$ ano ou $5.000 \mathrm{~m}^{3} / \mathrm{s}$, representando o potencial renovável de água que circula no aqüífero. A recarga natural ocorre por meio da infiltração direta das águas da chuva nas áreas de afloramentos das rochas da Formação Botucatu (Figura 1) e de forma indireta por infiltração vertical, ao longo das descontinuidades das rochas do pacote confinante sobrejacente, nas áreas onde a carga piezométrica favorece os fluxos descendentes. Devido a condições naturais, apenas uma porção das reservas reguladoras é possível de explotação. Em geral, esta parte é calculada entre $25 \%$ e $50 \%$ (REBOUÇAS, 1992) das reservas reguladoras, respectivamente entre 40 a $80 \mathrm{~km}^{3} / \mathrm{ano}$.

\section{FORMAÇÃO SERRA GERAL}

A Formação Serra Geral constitui uma ampla província magmática que no conjunto de todas as áreas por ela compreendidas, é definida como a maior manifestação ígnea não oceânica durante o Fanerozóico, recobrindo uma área superior a $1.200 .000 \mathrm{~km}^{2}$ na porção centro-sul do Brasil, noroeste do Uruguai, nordeste da Argentina e sudeste do Paraguai. De maneira generalizada, constituem a Formação Serra Geral termos petrológicos dominados por basaltos toleíticos e andesitos basálticos, ocorrendo subordinadamente riolitos e riodacitos (PEATE et al., 1992).

Do ponto de vista hidrogeológico, a Formação Serra Geral constitui um sistema aqüífero com baixas vazões (até $42 \mathrm{~m}^{3} / \mathrm{h}$ ), uma vez que a água armazena-se ao longo dos sistemas de fraturas e falhas associadas aos grandes lineamentos que cortam a bacia.

Em regiões onde a demanda é restrita ao abastecimento de pequenas propriedades, esse aqüífero constitui uma das principais fontes de água subterrânea, uma vez que os custos de explotação são baixos quando comparados aos de projetos no Aqüífero Guarani.

\section{GRUPO BAURU}

O Grupo Bauru, registro de sedimentação continental, é constituído por rochas lamíticas na base (Formação Araçatuba), gradando para arenitos e conglomerados no topo (formações Adamantina/Uberaba e Marília), depositados em cinco ambientes geneticamente ligados, constituindo um trato de sistema lacustre/aluvial. Suas fácies indicam processos sedimentares subaquosos (decantação), tracionais por correntes (fluvio-aluviais), e subaéreos (eólicos), sob condições climáticas semi-áridas (BATEZELLI, 2003; BATEZELLI et al., 2003a; BATEZELLI et al., 2003b; BATEZELLI et al., 2005 em preparação).

Distribui-se por uma área de $330.000 \mathrm{~km}^{2}$ nos Estados de São Paulo, Mato Grosso do Sul, Minas Gerais, Goiás e Mato Grosso, com espessura média de 200 metros.

As características litológicas e o intenso processo de cimentação carbonática conferem a essa unidade baixos valores de porosidade e permeabilidade. Assim, como o Aqüífero Serra Geral, a explotação de água subterrânea no Aqüífero Bauru se restringe ao centro-oeste do Estado de São Paulo e Triângulo Mineiro (MG) onde suas vazões são suficientes para suprir pequenas demandas.

\section{MATERIAL E MÉTODOS DE TRABALHO}

Para análise de bacia desenvolvida foram realizados estudos em diferentes escalas. Em princípio, foram feitas análises de imagens de satélite para extração de lineamentos de drenagem, resultando assim no mapa com as principais feições estruturais que seccionam a área de estudo (Figura 3). Esse mapa serviu de base para as interpretações estruturais relacionadas principalmente às deformações associadas aos eventos neotectônicos, importantes para a caracterização do aqüífero Serra Geral ("tipo fraturado"). A partir dessa análise foram identificados vários compartimentos estruturais, com direções de fraturas e falhas paralelas às descontinuidades do embasamento pré-cambriano, que foram reativações durante o Cenozóico.

O segundo passo foi a aquisição de dados de superfície e sub-superfície. As informações de superfície consistiram de descrição, documentação fotográfica de afloramentos do Grupo Bauru e coleta de amostras para análises petrográficas. Foram percorridos cerca de 6.000 $\mathrm{km}$ de rodovias e estradas em uma área aproximada de $65.000 \mathrm{~km}^{2}$, abrangendo o Triângulo Mineiro (extremo oeste de Minas 
Gerais), norte do Estado de São Paulo, Sul de Goiás e nordeste de Mato Grosso do Sul.

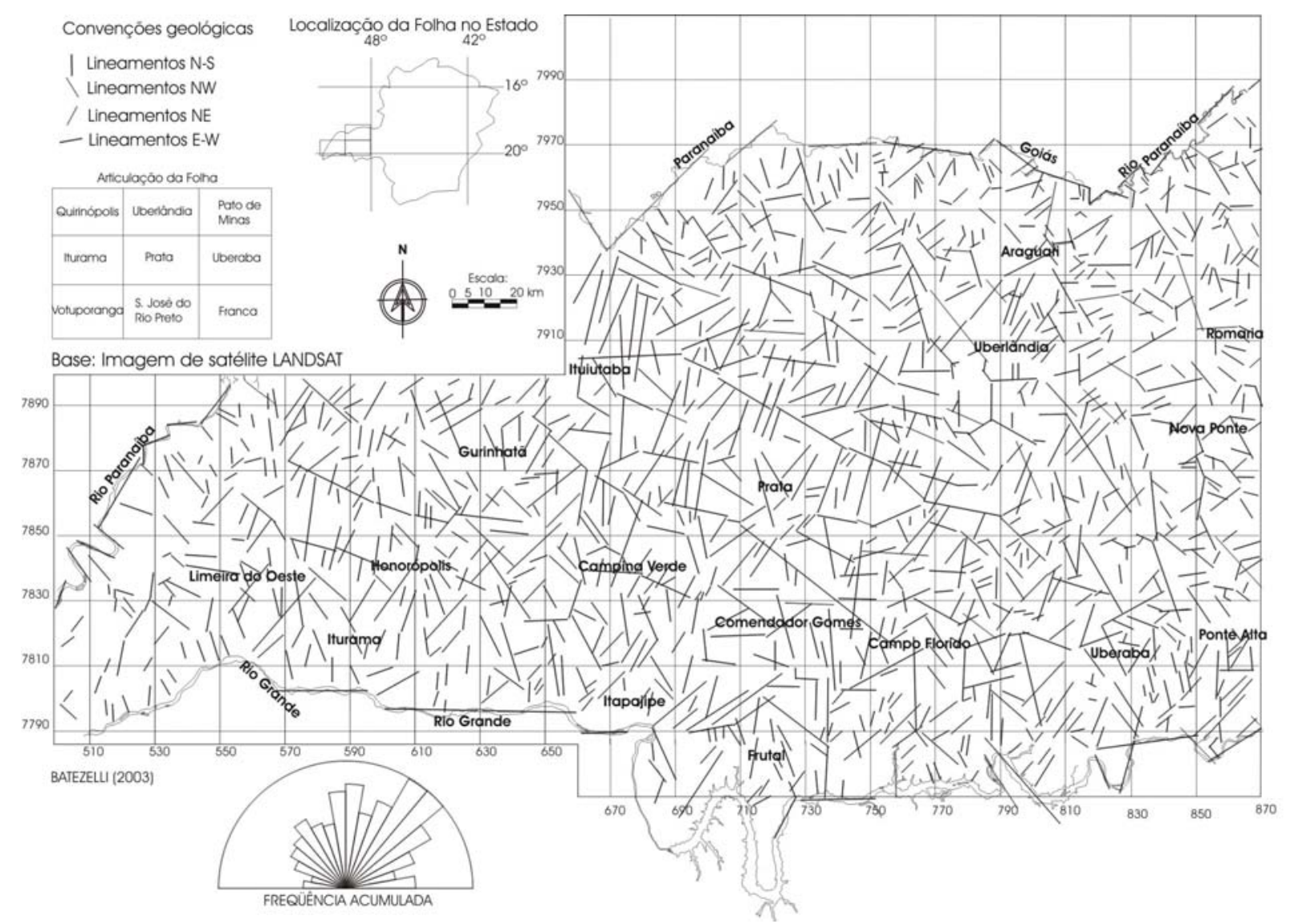

Figura 3 - Mapa de lineamentos de drenagem fotointerpretados a partir de imagem de satélite

(BATEZELLI, 2003).

A partir da aquisição de informações extraídas de perfis litológicos de poços tubulares profundos, adquiridos junto às empresas de perfuração e órgãos públicos do Estado de Minas Gerais, foi possível a elaboração de mapas que contemplam a distribuição, espessuras e comportamentos estruturais dos aqüíferos em sub-superfície. Como a maioria dos poços é pouco profunda, com médias em torno de 200 metros, não foi possível a elaboração de mapas de isoespessuras para o sistema de Aqüífero Botucatu. Para a elaboração do mapa de contorno estrutural do topo da Formação Botucatu foram utilizadas informações de poços das regiões adjacentes no norte do Estado de São Paulo, nordeste do Mato Grosso do Sul e Sul de Goiás.

\section{Arcabouço tectono-estratigráfico dos Aqüíferos Bauru, Serra Geral e Botucatu/Guarani no Triângulo Mineiro - Aplicação do Modelo}

A análise integrada de bacias sedimentares, utilizando técnicas estratigráficas baseadas em informações de afloramentos e poços, tem fornecido importantes subsídios na exploração de recursos minerais, sobretudo à indústria do petróleo. Nos últimos anos, a preocupação com as questões ambientais tem despertado em muitos pesquisadores o interesse na busca de métodos de estudos que auxiliem no planejamento urbano, principalmente na delimitação de áreas potenciais para recursos minerais voltados à construção civil e recursos hídricos subterrâneos. A esse respeito merecem destaque os trabalhos de SAAD (1990), CAMPANHA (1994), LANDIM et al. (2002) e BATEZELLI (2003).

Para se chegar aos resultados aqui apresentados, foram extraídos das colunas litológicas de cada poço os informações referentes à cota topográfica da boca do poço, espessura total do Grupo Bauru, cota do topo do basalto e espessura da Formação Serra Geral, e, cota topográfica do topo da Formação Botucatu. Além disso, também foram extraídas informações sobre espessura de sedimentos com granulometria abaixo de areia muito fina do Grupo Bauru, para confecção do mapa de fácies finas (Figuras 4 a 8 ). 
A existência de várias áreas deprimidas nessa porção da bacia fica evidenciada através da análise do mapa de isópacas do Grupo Bauru (Figura 4), onde essa unidade apresenta valores de espessuras maiores em relação à média regional (30 a $40 \mathrm{~m}$ ): Uberaba (60 - $70 \mathrm{~m}$ ), Ponte Alta (100 metros), Comendador Gomes (100 m), União de Minas (190 m), Limeira do Oeste (90 m), Gurinhatã (80 m), Fernandópolis (180 m) e General Salgado (180 m).
De maneira geral, as maiores espessuras preservadas do Grupo Bauru estão situadas no eixo Gurinhatã (MG) - General Salgado (SP) de direção norte-sul, coincidindo com a área de maior espessura de basaltos da Formação Serra Geral (Figura 7) e com a diminuição nos valores das cotas topográficas do topo dessa mesma unidade. (Figura 8).

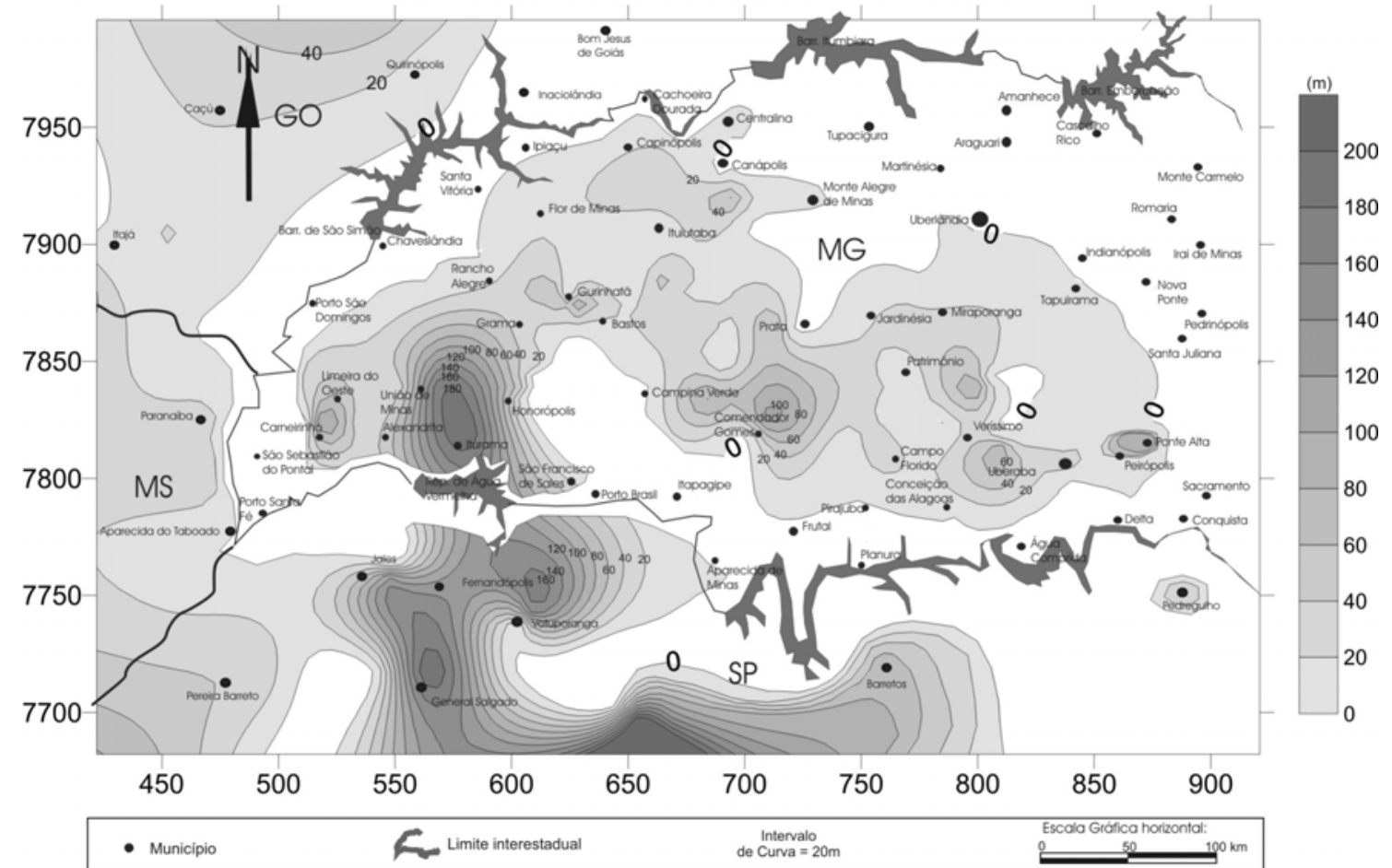

Figura 4 - Mapa de isópacas do Grupo Bauru no Triângulo Mineiro e áreas adjacentes.

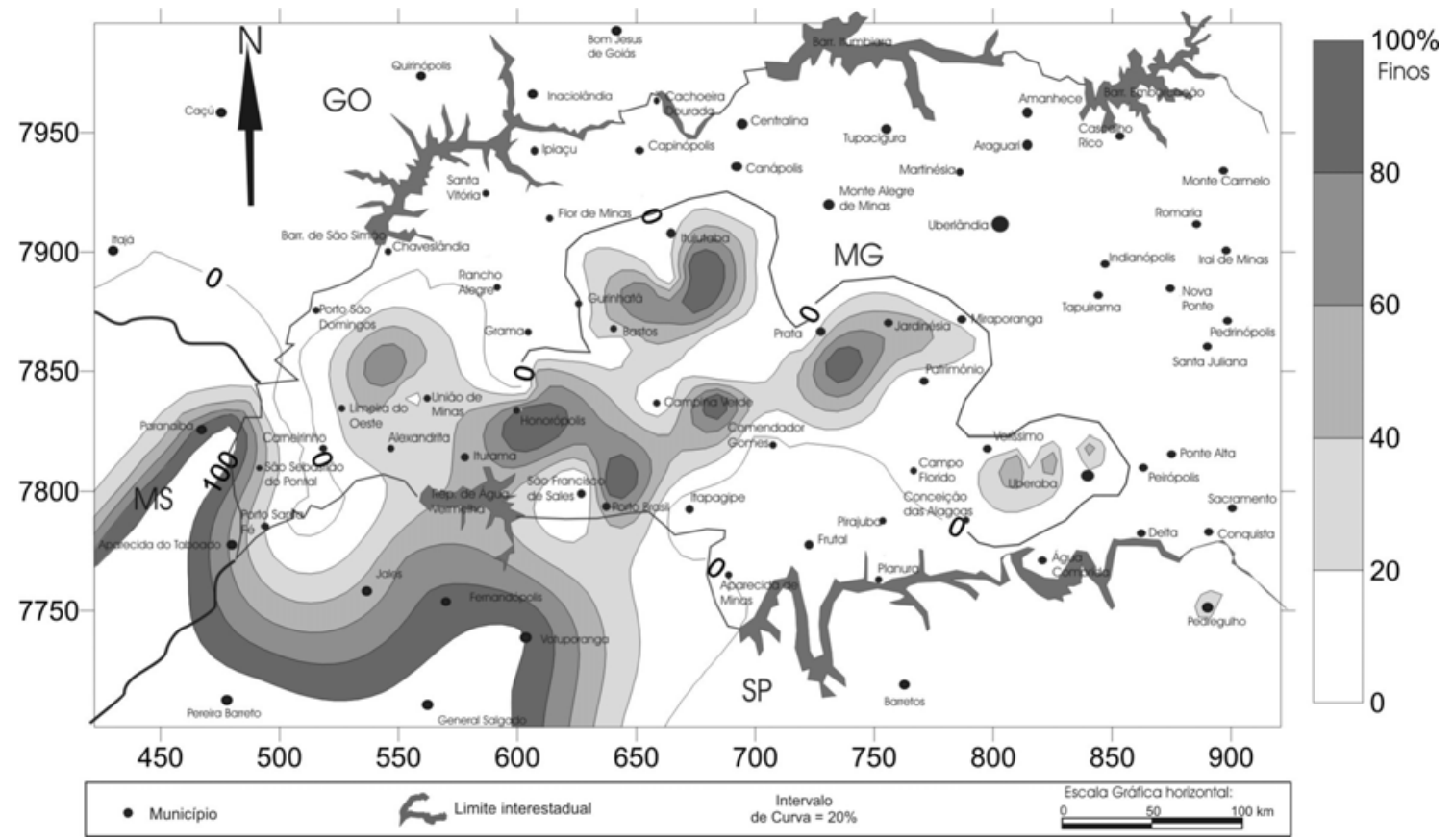

Figura 5 - Mapa de isoporcentagens de fácies finas (Associação de fácies I) do Grupo Bauru no Triângulo Mineiro e áreas adjacentes. 


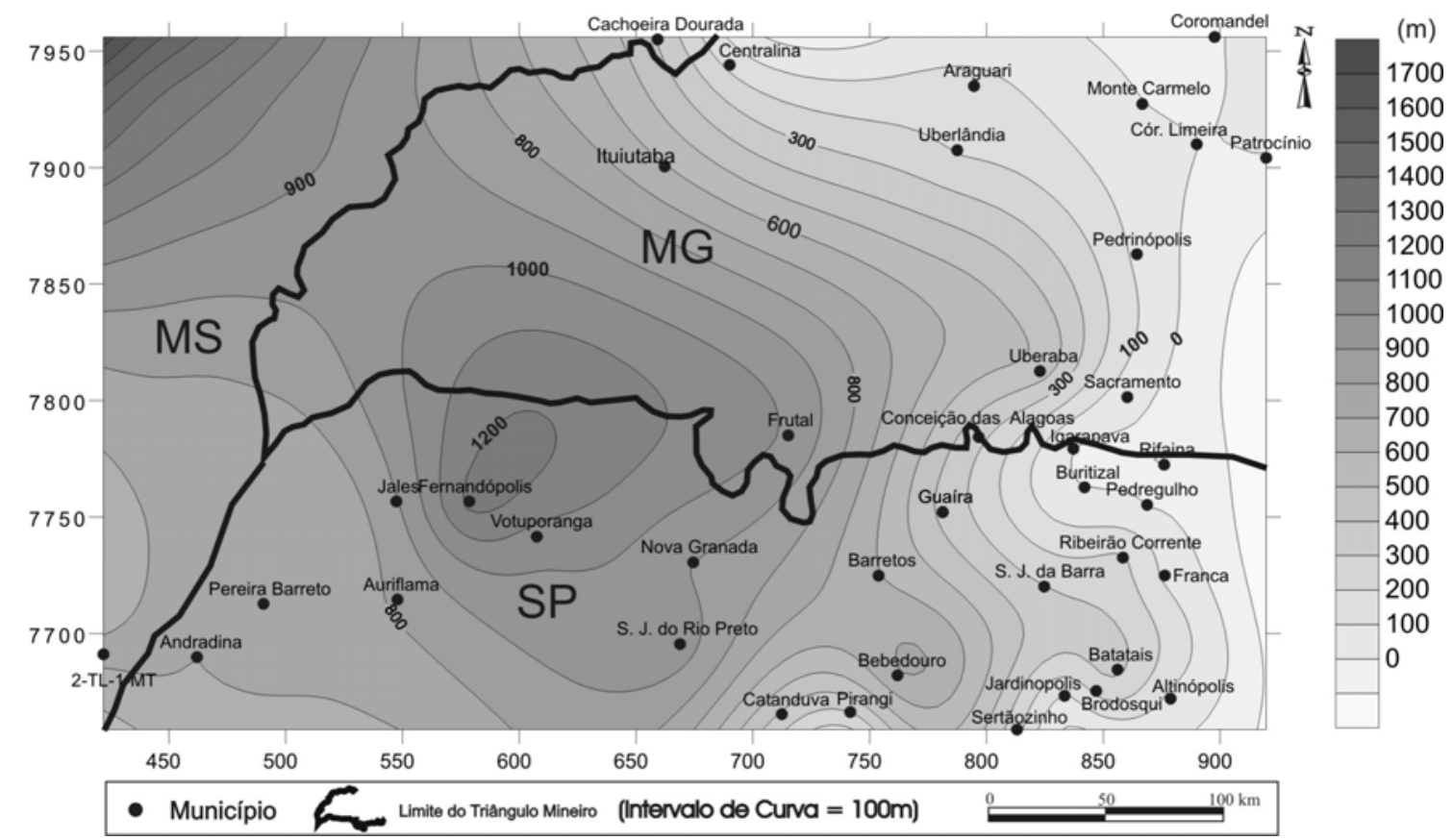

Figura 6 - Mapa de isólitas da Formação Serra Geral no Triângulo Mineiro e áreas adjacentes.

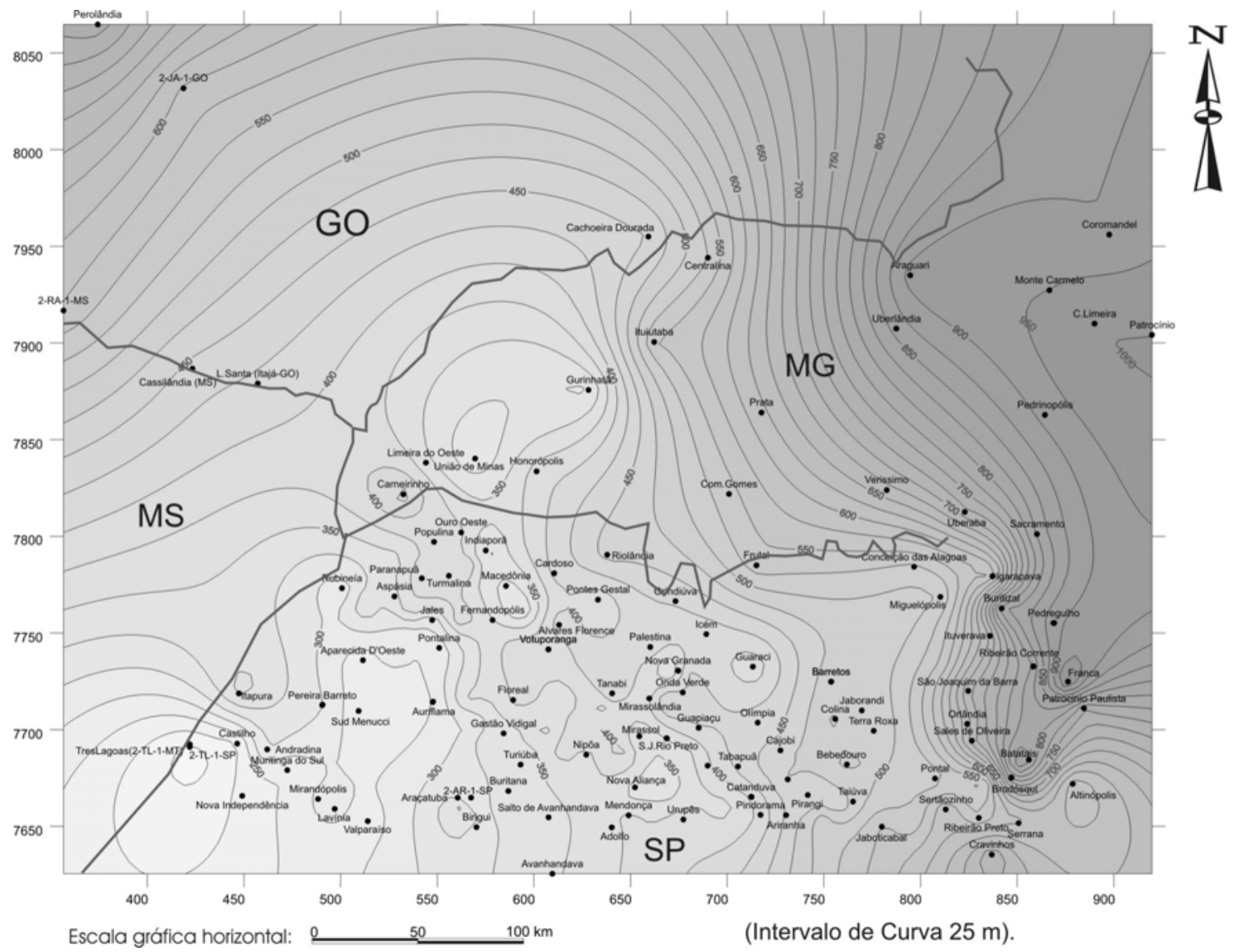

Figura 7 - Mapa de Contorno Estrutural do Topo da Formação Serra Geral no Triângulo Mineiro e áreas adjacentes. 


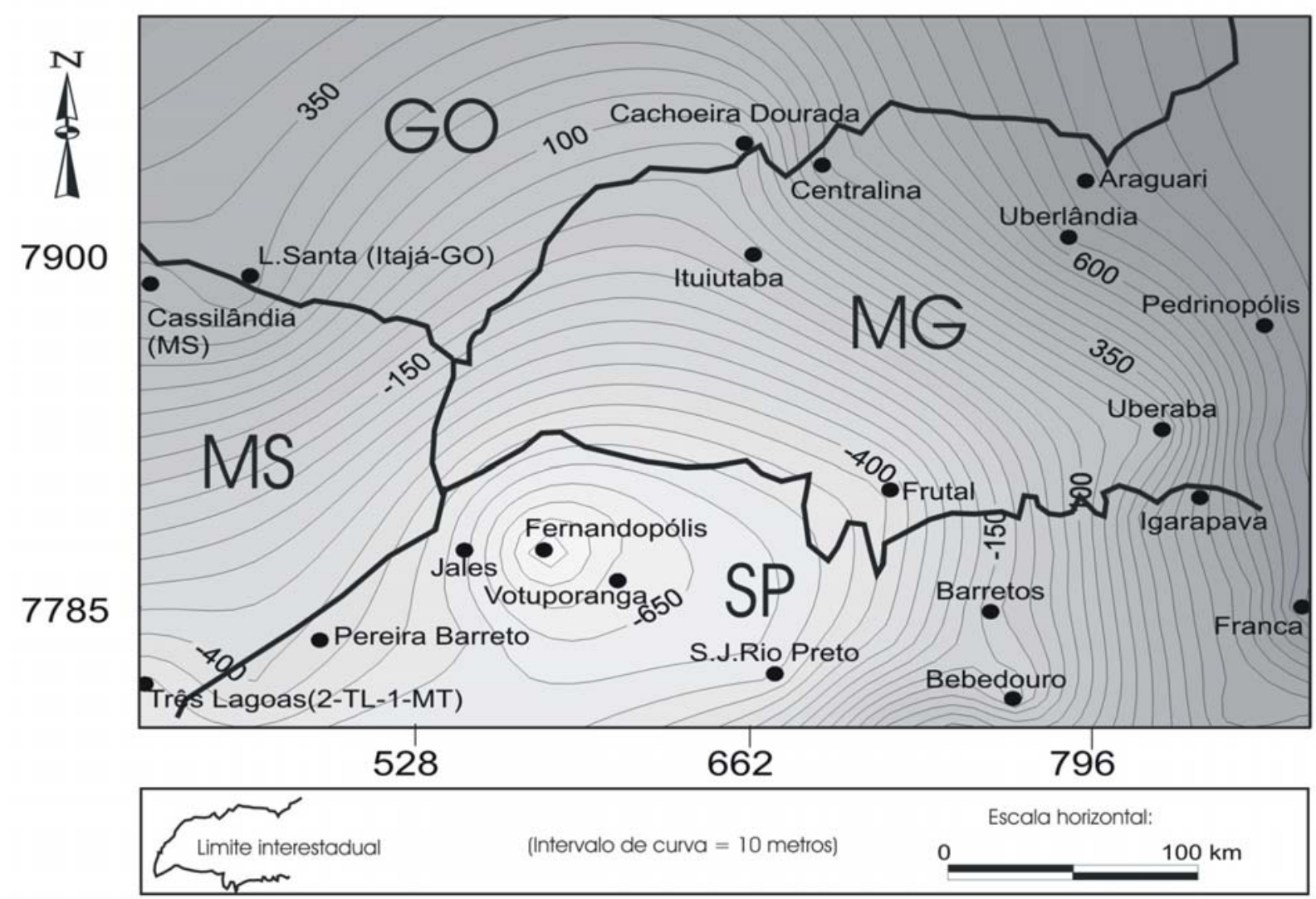

Figura 8 - Mapa de Contorno Estrutural do Topo da Formação Botucatu no Triângulo Mineiro e áreas adjacentes.

Na região balizada pelas cidades de Ponte Alta (MG), Conceição das Alagoas (MG) e Patrimônio do Rio do Peixe (MG), a espessura máxima preservada é da ordem de $160 \mathrm{~m}$. Esses depósitos estão alinhados segundo uma feição estrutural de direção SE-NW, denominada Sutura de Itumbiara (HASUI et al., 1989) (Figura 9).

No sudoeste de Goiás e nordeste do Mato Grosso do Sul, a espessura média do Grupo Bauru é da ordem de $60 \mathrm{~m}$. Na porção noroeste do estado de São Paulo está preservada uma grande espessura dessa unidade. A área balizada pelas cidades de Votuporanga, Fernandópolis, General Salgado e Jales, corresponde a uma grande depressão onde o acúmulo de sedimentos ultrapassou 180 m (Figura 4).

O mapa de isoporcentagens de fácies finas do Grupo Bauru (Figura 5) mostra uma área com maior ocorrência de lamitos no eixo Ituiutaba (MG) - Fernandópolis (SP), o que interfere nas características de permo-porosidade do aqüífero Bauru. No entanto, as fácies finas do Grupo Bauru, ocorrem em sua base em contato com os basaltos da Formação Serra Geral. O maior problema do Grupo Bauru com relação a diminuição das condições de permo-porosidade, reside no fato de que suas fácies arenosas, sobrejacentes aos lamitos, apresentam-se freqüentemente cimentadas por carbonato de cálcio (BATEZELLI et al., 2003b).

Muito embora ocorram cimentadas, as fácies arenosas do Grupo Bauru constituem o principal alvo das explotações de água subterrânea na região por parte de algumas prefeituras e pequenos agricultores, com vazões de até 20 $\mathrm{m}^{3} /$ hora. 


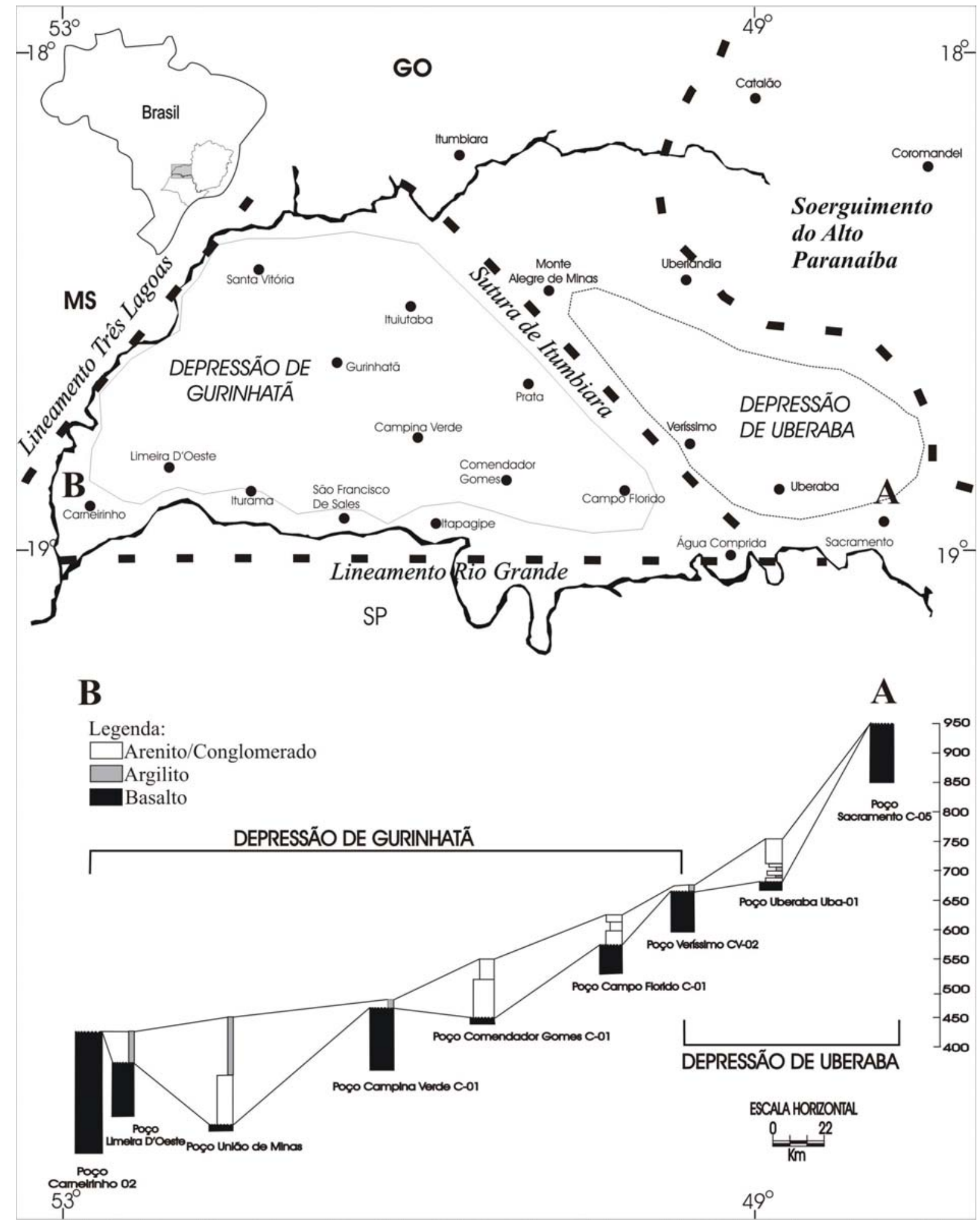

Figura 9 - Mapa de compartimentação estrutural do Triângulo Mineiro.

No mapa de isólitas de basalto da Formação Serra Geral (Figura 6), observa-se que a espessura da unidade aumenta de leste para oeste, onde chega a atingir valores acima de $1200 \mathrm{~m}$ na região de Fernandópolis (SP). O mapa de contorno estrutural do topo da Formação Serra Geral (Figura 7) mostra uma diminuição dos valores da cota topográfica (em relação ao nível do mar) no rumo ENE-WSW, coincidindo com a região de maior espessura. Constata-se nesse mapa uma área mais subsidente na parte oeste do Triângulo Mineiro (MG) e noroeste do estado de São Paulo, compreendida pelos municípios de Limeira do Oeste, União de Minas, Gurinhatã, Votuporanga, General Salgado e Jales, na qual o menor valor verificado foi da isolinha de $325 \mathrm{~m}$ 
de altitude, em relação ao nível do mar. No extremo leste do Triângulo Mineiro, os valores obtidos para o topo dos basaltos foram de até 900 $m$ de altitude (Figura 7). Para elaboração de projetos de explotação de água subterrânea desse sistema aqüífero, sua espessura tem pouca importância na área de estudo quando comparado com informações referentes ao grau de fraturamento e a cota topográfica de seu topo. Dessa maneira, o mapa de lineamentos de drenagem assume papel importante na definição de áreas favoráveis a projetos relacionados ao aqüífero Serra Geral (Figura 3).

De maneira geral, a prospecção e explotação de água subterrânea no Aqüífero Serra Geral, na região do Triângulo Mineiro, é muito maior do que no Aqüífero Bauru, sobrejacente. Isso ocorre devido ao intenso grau de fraturamento dessa unidade, relacionado a reestruturação tectônica terciária. As principais direções de fraturamento são NW, EW e NE, estão intimamente relacionadas a três grandes lineamentos estruturais pré-cambriano reativadas durante o Mesozóico e Cenozóico, denominados por HASUI et al. (1989), de Sutura de Itumbiara, Lineamento do Rio Grande e Lineamento de Três Lagoas, respectivamente (Figura 9).

Dado ao elevado grau de fraturamento dos basaltos, o sistema de aqüífero Serra Geral atinge vazões de até $42 \mathrm{~m}^{3} /$ hora, sendo suficiente para o abastecimento de pequenas cidades, agricultores e empresas de pequeno a médio porte.

Com relação ao sistema de aqüífero Botucatu (Guarani), as informações levantadas no desenvolvimento do projeto não tiveram a mesma densidade de dados quando comparadas às unidades sobrejacentes. Na região do Triângulo Mineiro (MG), até o ano de 2003, apenas dois poços foram perfurados visando explotação de água no sistema Botucatu/Guarani, sendo um na cidade Uberaba e outro em Frutal (COPASA, 1999). Nos estados de Goiás e Mato Grosso do Sul, poucas são as informações disponíveis, uma vez que as companhias de saneamento não dispõem de cadastros atualizados. Já na região norte do Estado de São Paulo, o aqüífero Botucatu é o principal alvo de explotação de água subterrânea, conferindo àquela região uma maior densidade de dados de poços tubulares profundos.

Dada as suas características litológicas e distribuição em área, a Formação Botucatu constitui atualmente um dos maiores sistemas de aqüífero subterrâneo do mundo, com reservas da ordem de 45 trilhões de metros cúbicos, e vazões que variam de 100 a $300 \mathrm{~m}^{3} /$ hora (GEOPLAN, 1999). Nos países limítrofes com o Brasil, esse sistema é referido como Aqüífero Guarani.

Para projetos que visam explotação do Sistema de Aqüífero Botucatu/Guarani, a definição da espessura dos basaltos da Formação Serra Geral e a cota topográfica do topo da Formação Botucatu assume importância fundamental, uma vez que definem os custos.

Como exemplo de aplicação das informações levantadas com a Análise de Bacia, cita-se o município de Ituiutaba, na região noroeste do Triângulo Mineiro, onde não existe nenhum poço perfurado que alcance o Aqüífero Guarani.

As informações obtidas para o Triângulo Mineiro (MG) mostram que na região em apreço, o Grupo Bauru possui espessura máxima de até 50 metros, preservado em depressões localizadas (Figura 4). A principal unidade aflorante é constituída pelos basaltos da Formação Serra Geral, sendo que tanto no mapa de isoespessura desses basaltos, como no mapa de contorno estrutural do topo da Formação Botucatu, a espessura média dos basaltos é de $600 \mathrm{~m}$ (Figuras 6 e 8$)$

O mapa de lineamentos estruturais fotointerpretados a partir de imagens de satélite (Figura 3), e as medidas de falhas e fraturas de afloramentos, fornecem importantes dados sobre a geologia estrutural da área. Os dados obtidos mostram que as principais feições estruturais ocorrem na direção SE-NW, coincidentes com a Sutura de Itumbiara (HASUI et al., 1989).

Com base na integração desses elementos, é possível sintetizar, em um modelo geológico esquemático (Figura 10), a configuração dos principais aqüíferos aí existentes, direcionando prováveis projetos de locação de poços tubulares profundos. 


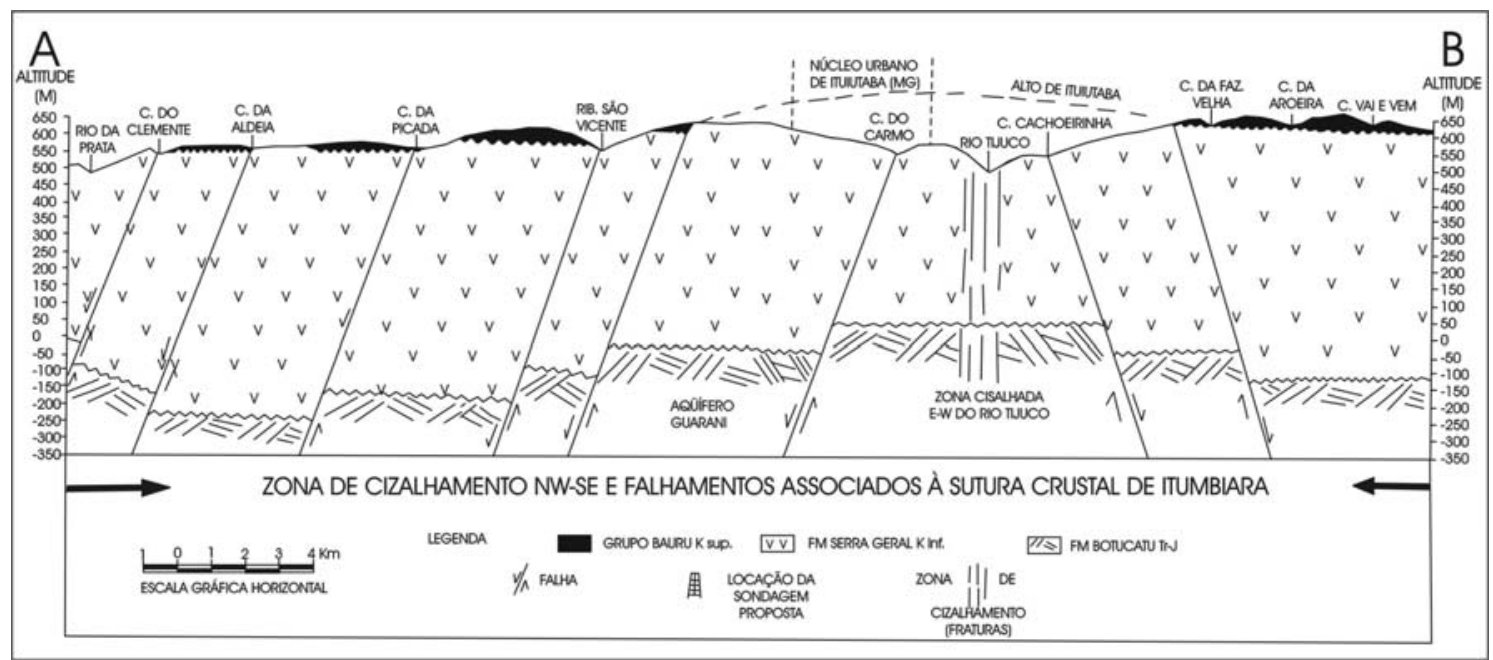

Figura 10 - Seção geológica hipotética (NNE-SSW), da região de Ituiutaba (MG), baseado em informações de superfície e sub-superfície.

\section{DISCUSSÃO}

A partir da análise de dados de vazões, constatou-se que o aqǘffero Bauru (granular) possui uma variação de 0,42 a $15,00 \mathrm{~m}^{3} /$ hora, enquanto que no Serra Geral (fraturado) a variação é de 0,27 a $42,00 \mathrm{~m}^{3} /$ hora. Como as vazões não são suficientes para o abastecimento em grande escala, vários poços têm sido perfurados, fazendo com que esses sistemas de aqüíferos sofram considerável rebaixamento de seu nível.

Através da análise de bacia verificou-se que na região da Depressão de Gurinhatã (oeste do Triângulo Mineiro), o sistema aqüífero Bauru possui as maiores vazões (até $20,0 \mathrm{~m}^{3} /$ hora), ao contrário da região de Uberaba (Depressão de Uberaba), onde as vazões médias são da ordem de $1,0 \mathrm{~m}^{3} /$ hora. Essa constatação é explicada pelo fato de que a região da Depressão de Uberaba sofreu um processo de cimentação mais intenso, obliterando as características de permoporosidade das rochas. $\mathrm{Na}$ depressão de Gurinhatã, embora haja uma maior porcentagem de fácies finas, os corpos arenosos dispõem de maior continuidade lateral, o que favorece uma maior interligação do sistema aqüífero. Nessa porção houve também maior dissolução dos cimentos das fácies arenosas.

As águas subterrâneas da área de estudo possuem pH básico com valores entre 7 e 10 . São, no geral, de boa qualidade para os consumos humano, industrial e agrícola. Os teores dos cátions como o cálcio, sódio, potássio, magnésio estão dentro dos limites estabelecidos pela resolução do CONAMA (1986), para águas da classe 1 (CORSI, 2003). Os ânions, cloreto, bicarbonato, carbonato, sulfato e nitrato também estão dentro dos limites do CONAMA (op. cit.).
O manganês, na forma de constituinte secundário, ocorre em alguns poços, sempre dentro do limite tolerado.

Somente em dois poços, um no município de Carneirinho e outro em Fátima do Pontal, o teor de $3,2 \mathrm{mg} / \mathrm{L}$ de fluoreto está acima do limite estabelecido pelo CONAMA (op. cit.) de 1,4 $\mathrm{mg} / \mathrm{L}$. Neste caso, essas águas são prejudiciais ao ser humano, podendo causar manchas nos dentes (fluorose dental) e deformação dos ossos, bem como pode ser tóxico para os vegetais (FEITOSA e MANOEL FILHO, 1997).

Nas regiões de Conceição de Alagoas e Cachoeira Dourado situadas ao longo da Sutura de Itumbiara, há registros de águas subterrâneas termais $\left(40-45^{\circ} \mathrm{C}\right)$. Tal fato abre um novo leque de oportunidades, para futuros investimentos nos setores industrial e lazer.

\section{CONCLUSÕES}

Atualmente a Bacia do Paraná ocupa posição de destaque por abrigar importantes sistemas de aqüíferos subterrâneos, capazes de abastecer importantes centros urbanos.

$\mathrm{Na}$ sua porção centro-norte, sobretudo na região do Triângulo Mineiro e áreas adjacentes, verificam-se dois tipos principais de aqüíferos subterrâneos: fraturado e granular. $\mathrm{O}$ aqüífero fraturado aplica-se às rochas basálticas da Formação Serra Geral, enquanto que o granular às rochas pertencentes a Formação Botucatu/Guarani e ao Grupo Bauru.

A existência de muitas depressões comprova que a área esteve sujeita a esforços relacionados a reativação de estruturas do embasamento. A correlação estratigráfica encontrada entre essas depressões indica que o evento tectônico responsável por sua gênese foi posterior a 
sedimentação, e está relacionado à reativação tectônica terciária.

As maiores espessuras preservadas para o Grupo Bauru, no Triângulo Mineiro, encontramse alinhadas segundo a direção NW-SE, demonstrando que a Sutura de Itumbiara (HASUI et al., 1989) foi o elemento estrutural que condicionou as deformações naquela região da bacia. Além disso, é importante ressaltar que sobre essa importante feição estrutural ocorreu um intenso processo de cimentação das rochas do Grupo Bauru por carbonato de cálcio, responsável pela baixa permo-porosidade verificada nessa porção da bacia.

A diminuição dos valores das cotas topográficas do topo da Formação Serra Geral, assim como de seu espessamento em direção a SW, na área de estudo, sugerem atuação do Soerguimento do Alto Paranaíba nessa configuração.

O reconhecimento dessas características estruturais permite um melhor direcionamento na locação dos poços tubulares profundos, obtendose desta forma melhores vazões, a exemplo do modelo exploratório para o município de Ituiutaba (MG) (Figura 10).

Conforme mencionado anteriormente, o aqüífero fraturado é explotado amplamente na região, sobretudo por empresas de pequeno a médio porte e algumas prefeituras. Assim, o critério estrutural assume um caráter essencial no que diz respeito à alta produtividade dos poços. Dessa forma, as maiores vazões encontradas situam-se na porção centro-leste do Triângulo Mineiro, coincidentes com a direção de fraturamento NW-SE, ao longo da Sutura de Itumbiara.
No que se refere ao aqüífero Bauru os dados mostram que na região centro-oeste do Triângulo Mineiro tem-se os maiores valores de vazão. Essa área é coincidente com áreas deprimidas nas regiões de Limeira do Oeste, União de Minas e Gurinhatã, todas elas pertencentes à Depressão de Gurinhatã (Figura 4).

Com relação ao Aqüífero Guarani (Formação Botucatu), a falta de dados para análise desse importante aqüífero, fez com que fosse realizado um levantamento de informações em outras áreas tais como no Estado de São Paulo, em municípios situados entre os rios Grande e Tietê, bem como em Goiás e Mato Grosso do Sul. Os resultados encontram-se expressos na forma de mapas de isólitas e contorno estrutural do topo da Formação Serra Geral (Figuras 6 e 7 ) e de contorno estrutural do topo da Formação Botucatu (Figura 8). Através desses mapas, constata-se que o sistema Botucatu, principal aqüífero da Bacia do Paraná, ocorre em cotas cada vez mais baixas a partir da região leste do Triângulo Mineiro (MG) até a região norte do Estado de São Paulo.

Frente à crescente demanda e às baixas vazões alcançadas nos aqüíferos Bauru e Serra Geral, a análise de bacia aqui realizada sugere que as perfurações tenham como prospecto principal o sistema aqüífero Botucatu, a exemplo de cidades como Uberaba e Frutal, onde as vazões são da ordem de 153,00 $\mathrm{m}^{3} / \mathrm{h}$. Com vazões bem maiores que os demais aqüíferos, o Aqüífero Guarani destaca-se como principal alvo para explotação de água subterrânea, capaz de suprir necessidades de grandes indústrias e centros urbanos.

\section{REFERÊNCIAS}

ALMEIDA, F. F. M. de, MELO, M. S. de. A Bacia do Paraná e o Vulcanismo Mesozóico. In: Mapa Geológico do Estado de São Paulo. Instituto de Pesquisas Tecnológicas do Estado de São Paulo S/A. Publicação IPT, 1184, 1981. v. 1, p. 46-81. Escala 1:500000.

ARAÚJO, L.M. FRANCIA, A.B. Y POTTER, P.E. 1995. Acuífero Gigante del Mercosur en Argentina, Brasil, Paraguay y Uruguay: Mapas hidrogeológicos de las formaciones Botucatú, Piramboia, Rosario del Sur, Buena Vista, Misiones y Tacuarembó. UFPR y Petrobras, $16 \mathrm{p}$ Curitiba, Paraná - Brasil.

BATEZELLI, A. Análise da Sedimentação Cretácea no Triângulo Mineiro e sua
Correlação com Áreas Adjacentes, 2003. Rio Claro, SP. 183 p. (Tese de Doutoramento) Instituto de Geociências e Ciências Exatas, Universidade Estadual Paulista.

BATEZELLI, A.; SAAD, A. R.; ETCHEBEHERE, M. L. de C.; PERINOTTO, J. A. de J.; FULFARO, V. J. Análise Estratigráfica Aplicada À Formação Araçatuba (Grupo Bauru Ks) No Centro-Oeste Do Estado De São Paulo. Geociências, v.22, n.o Especial, p. 05-19, 2003a. BATEZELLI, A.; GOMES, N. S.; PERINOTTO, J. A. de J. Petrografia E Evolução Diagenética Dos Arenitos Da Porção Norte E Nordeste Da Bacia Bauru (Cretáceo Superior). Revista Brasileira de Geociências, 2003b, (no prelo). 
BATEZELLI, A.; SAAD, A. R.; LANDIM, P. M. B.; FULFARO, V. J.; PERINOTTO, J. A. de J.; CORSI, A.C. Basin Basin Analysis Applied To The North and Northeast Portion Of The Bauru Basin (Late Cretaceous): New Data on The Paleoenvironment and Paleogeography . (Em preparação - 2005).

CAMPANHA, V. A. A Arquitetura Deposicional da Bacia Sedimentar de Taubaté, SP, Como Subsídio à Delimitação das Zonas de Produção Mineral. Rio Claro, SP, 1994. 193 p. (Tese de Doutoramento) - Instituto de Geociências e Ciências Exatas, Universidade Estadual Paulista.

CAMPOS, L. F. G. De Seç̧ão Geológica. In: DERBY, O. A. Relatório da Comissão Geographica e Geológica da Província de São Paulo. Jorge Secker, 1889. P. 21-34.

CONSELHO NACIONAL DE MEIO AMBIENTE Resolução do CONAMA, 1984/86. Brasília: SEMA, 96 p., 1986.

COPASA - Companhia de Saneamento de Minas Gerais. Relatórios Técnicos de Poços Tubulares Profundos. Relatório interno Inédito. 1999.

CORSI, A. C. Compartimentação morfoestrutural da região do Triângulo Mineiro (MG) aplicada a exploração de recursos hídricos subterrâneos, 2003. Rio Claro, SP. 231 p. (Tese de Doutoramento) Instituto de Geociências e Ciências Exatas, Universidade Estadual Paulista.

FEITOSA, F. A. C. e MANOEL FILHO, J. Hidrogeologia - Conceitos e Aplicação. Fortaleza: CPRM, LABHID - UFPE, 412 p., 1997.

GEOPLAN - Sistemas de Águas e Efluentes. Relatórios Técnicos de Poços Tubulares Profundos. Relatório interno. Inédito. 1999.

HASUI, Y.; HARALYI, N. L. E.; MIOTTO, J. A.; SAAD, A. R.; CAMPANHA, V. A.; HANZA, V. M.; FRANGIPANI, A.; PULEGHINI, F. P. Compartimentação Estrutural e Evolução Tectônica do Estado de
São Paulo. São Paulo: 1989, 2v. IPT, (Relatório 27.394).

HIRATA, R. Recursos Hídricos. IN: TEIXEIRA, W.; TOLEDO, M. C. M. de; FAIRCHILD, T. R.; TAIOLI, F. Decifrando a Terra. São Paulo, Oficina de Texto, p. 421-442, 2002.

LANDIM, P. M. B.; FULFARO, V. J.; SAAD, A. R. PERINOTTO, J. A.DE J.; BATEZELLI, A.; CORSI, A. C. A Bacia Bauru no Triângulo Mineiro (MG): Análise de Bacia como Proposta de uma nova Estratégia Exploratória para Recursos Minerais e Hídricos. Projeto FAPESP 99/00323-5, Relatório Final, São Paulo, 2002.

MILANI, E. J. Evolução Tectono-estratigráfica da Bacia do Paraná e seu Relacionamento com a Geodinâmica Fanerozóica do Gondwana Sul-ocidental 1997. 255 p. Tese (Doutorado) Programa de Pós-Graduação em Geociências, Universidade Federal do Rio Grande do Sul, Porto Alegre (RS).

PEATE, D. W.; HAWKESWORTH, C. J. e MANTOVANI, M. S. M. Chemical Stratigraphy of the Paraná Lavas (South America): Classification of Magma Types and their Spatial Distribution. Bulletim of Volcanology, vol. 55: 119-139, 1992.

REBOUÇAS, A.C. 1992. Recursos Hídricos Subterrâneos da Bacia do Paraná: Análise da pré-viabilidade. Tese de Livre Docência. Universidade de São Paulo, 143p., 1997.

SAAD, A. R. Potencial Econômico da Bacia de Taubaté (Cenozóico do Estado de são Paulo, Brasil) nas Regiões de Jacareí, Taubaté, Tremembé e Pindamonhangaba. Rio Claro, SP, 1990. 173 p. (Tese de Doutoramento) Instituto de Geociências e Ciências Exatas, Universidade Estadual Paulista.

ZALAN, P. V.; WOLF, S.; CONCEIÇÃO, J. C. J.; MARQUES, A.; ASTOLFI, M. A. M.; VIEIRA, I. S.; APPI, C. T.; ZANOTTO, O. A. Bacia do Paraná. In: RAJA GABAGLIA, G. P. e MILANI, E. J. Origem e Evolução de Bacias Sedimentares. Rio de Janeiro, Gávea, p. 135 168. 1990. 
Análise de bacia aplicada às unidades mesozóicas do Triângulo Mineiro (sudeste do Brasil): uma estratégia na prospecção... 